\title{
Characterization of $\mathrm{CdS} / \mathrm{ZnS}$ and $\mathrm{CdS} / \mathrm{CoS}$ Multilayer Thin Films Synthesized by Chemical Bath Deposition
}

\author{
Tizazu Abza ${ }^{1, *}$, SisayTadesse ${ }^{1}$ and Dinsefa Mensure Andoshe ${ }^{2}$ \\ ${ }^{1}$ College of Natural and Computational Science, Hawassa University, Ethiopia \\ ${ }^{2}$ Department of Materials Science and Engineering, Adama Science and Technology University, Ethiopia
}

Received: 20 Apr. 2020, Revised: 17 Oct. 2020, Accepted: 24 Nov. 2020

Published online: 1 Jan. 2021

\begin{abstract}
In this work multilayer films of $\mathrm{CdS} / \mathrm{ZnS}$ and $\mathrm{CdS} / \mathrm{CoS}$ were prepared using the chemical bath deposition technique. The influence of substrate materials on structural, morphological, compositional and optical properties of the films was investigated. The powder X-ray diffraction (XRD) pattern of $\mathrm{CdS} / \mathrm{ZnS}$ thin film showed nearly similar structure to that of the cubic $\mathrm{ZnS}$ structure. The XRD pattern of $\mathrm{CdS} / \mathrm{CoS}$ thin films confirmed the co-existence of hexagonal and orthorhombic CdS phases. A cubic CdS structure is observed for CdS/glass thin film. The scanning electron microscopy (SEM) micrograph of CdS/glass film revealed spherical grains of size $125 \mathrm{~nm}$ covering the substrate uniformly without voids and cracks. The as large grain size as $800 \mathrm{~nm}$ with distinct grain boundaries was observed for $\mathrm{CdS} / \mathrm{ZnS}$ multilayer film with some voids on the surface. The SEM micrograph of CdS/CoS thin film showed spherical surface grains of size $450 \mathrm{~nm}$ on flat and compact background. The energy dispersive X-ray spectra of single and multilayer $\mathrm{CdS}$ films confirmed the presence of $\mathrm{Cd}$ and $\mathrm{S}$. The optical analysis of the $\mathrm{CdS} /$ glass, $\mathrm{CdS} / \mathrm{ZnS}$ and $\mathrm{CdS} / \mathrm{CoS}$ thin films confirmed band gaps of 2.5, 2.3 and $2.27 \mathrm{eV}$ respectively.

Keywords: heterostructure, Crystal structure, Cadmium sulfide, Cobalt sulfide, Zinc sulfide, Chemical bath,
\end{abstract}

\section{Introduction}

Cadmium sulfide (CdS) is an important II-VI group semiconductor material owing to its optical properties, photoconductivity, high electron affinity and stability [1]. It exhibits n-type conductivity because of native defects such as sulfur vacancies and interstitial cadmium [2]. CdS is widely used in optical detectors, optoelectronic devices and as a window material in various heterojunction solar cells [3]. CdS thin films can be prepared by different techniques such as closed space sublimation [4], RF magnetron sputtering [5], chemical bath deposition (CBD) [1, 3], vacuum evaporation [6], and spray pyrolysis [2]. CBD of CdS is a common practice since 1960s [7]. The CBD has many benefits like low cost for equipment and operation, simplicity in operation, low deposition temperature, low energy consumption, and large area deposition in a single procedure $[8,9]$. The nature of chemical bath deposited thin film depends on the preparation parameters such as nature of precursors [10-12], the deposition temperature [13, 14], $\mathrm{pH}$ [15-17], duration [18-20] and the substrate type [21-23]. Any solid material that does not dissolve in the chemical bath can be used as a substrate. However, type of substrate has substantial impact on the structural, optical, morphological and other properties of a film [24]. Glass is commonly used substrate for the deposition of CdS films by CBD technique. Other materials like polycarbonate, polyethylene terephthalate, Si wafer and indium-tin-oxide were also used as a substrate to deposit CdS. The substrate surface treatment either by heat or by chemicals also modifies the film properties [3, 25-28]. A semiconductor multilayers film, heterojunction, is formed when a semiconductor substrate is used to deposit another semiconductor of dissimilar bandgap and lattice constants. Semiconductor multilayer thin films are the basics of heterostructure devices that exploits the interface properties of these structures. Such structures inject nonequilibrium charge carriers, control the type of conductivity and other fundamental parameters: band gaps, effective mass of the charge carriers and the mobilities, refractive indices, the electron energy spectrum etc. inside the semiconductor crystals and devices [29]. The operation of semiconductor lasers, light-emitting diodes, photodetectors, highest-performance optical sources and detectors, and high-speed and high-frequency digital and analog devices exploit the heterostructure of semiconductors $[30,31]$.

In this work, we report on the structural, optical and 
morphological properties of chemical bath deposited $\mathrm{CdS}$ thin films and its heterojunctions with $\mathrm{ZnS}$ and CoS. The heterojunction of the $\mathrm{CdS}$ with $\mathrm{ZnS}$ and several types of their mixtures can be used as an n-type buffer layer to form thin film heterojunction solar cells [32, 33], quantum wells [34], light emitting devices [35] etc. Similarly, heterostructure of $\mathrm{CdS}$ and various phases of cobalt sulfide, like Co9S8 and Co4S3, are currently used for improving photocatalytic hydrogen production [36-38]. There are very few reports on chemical bath deposited heterojunctions of the $\mathrm{CdS}$ with $\mathrm{ZnS}$ $[9,32]$. However, to the best of our knowledge there are no reports on chemical bath deposited heterostructure of $\mathrm{CdS}$ with CoS.

\section{Experimental Section}

\subsection{Synthesis of the Thin Films}

In the deposition of $\mathrm{CdS} / \mathrm{ZnS}$ and $\mathrm{CdS} / \mathrm{CoS}$ multilayers, the $\mathrm{ZnS}$ and $\mathrm{CoS}$ layers were first prepared on soda lime glass substrates. Before the deposition of the $\mathrm{ZnS}$ and $\mathrm{CoS}$, the soda lime glass slides were immersed in nitric acid for $12 \mathrm{~h}$ and in ethanol for $30 \mathrm{~min}$, consecutively. Then the substrates were cleaned by distilled water ultrasonically and dried under ambient conditions. Analytical grade cadmium acetate (BDH), Zinc acetate (CARLO ERBA), cobalt acetate (Loba Chemie), thioacetamide (Titan), and $\mathrm{Na}_{2} E D T A$ (Fine Chemicals) were used as starting reagents. The CoS substrate was prepared on the cleaned soda lime glass substrate from a solution of $1 \mathrm{M}(10 \mathrm{ml})$ cobalt acetate, 0.2 $\mathrm{M}(9 \mathrm{ml}) \mathrm{Na}_{2} E D T A, 1 \mathrm{M}(10 \mathrm{ml})$ thioacetamide and $61 \mathrm{ml}$ distilled water at $\mathrm{pH}$ of 6 for $90 \mathrm{~min}$. Similarly, the $\mathrm{ZnS}$ substrate was prepared on soda lime glass substrate from a solution containing $0.1 \mathrm{M}(15 \mathrm{ml})$ zinc acetate, $0.2 \mathrm{M}(2 \mathrm{ml})$ $N a_{2} E D T A, 1 \mathrm{M}(7 \mathrm{ml})$ thioacetamide and $36 \mathrm{ml}$ distilled water at $\mathrm{pH}$ of 2.5 for $100 \mathrm{~min}$. After their corresponding deposition period, the $\mathrm{ZnS}$ and the $\mathrm{CoS}$ thin films were taken out of the chemical baths, washed with distilled water thoroughly and dried in ambient conditions before used for the preparation of the CdS films. The CdS thin films were deposited on soda lime glass (CdS/glass), $\mathrm{ZnS}$ coated soda lime glass $(\mathrm{CdS} / \mathrm{ZnS})$ and $\mathrm{CoS}$ coated soda lime glass $(\mathrm{CdS} / \mathrm{CoS})$ substrates from a solution of $0.1 \mathrm{M}(15 \mathrm{ml})$ cadmium acetate, $0.2 \mathrm{M}(2 \mathrm{ml}) N a_{2} E D T A, 1 \mathrm{M}(7 \mathrm{ml})$ thioacetamide and $36 \mathrm{ml}$ distilled water at $\mathrm{pH}$ of 2.5 for 100 min. The bath temperature of all the depositions carried out in the present work was adjusted to $80{ }^{\circ} \mathrm{C}$. The optical, morphological, compositional and structural properties of the single and multilayer films were characterized by UVVis spectrometer, scanning electron microscope (SEM), energy dispersive X-ray analyzer (EDX) and X-ray diffractometer respectively.

\subsection{Characterization of the Thin Films}

Structural characterization of the films was carried by Bruker D8 X-ray diffractometer (XRD) with $\mathrm{CuK} \alpha(\lambda=1.5406 \AA)$ radiation working at $40 \mathrm{~mA}$ and $40 \mathrm{kV}$ at a scan rate of $0.03 \%$ s. The XRD patterns were analyzed by matching the observed peaks with the standard JCPDS files. The surface morphology and composition of single and multilayer thin films were studied by ZEISS sigma field effect scanning electron microscopy (FE-SEM) attached with ZEISS Analysis Station energy dispersive X-ray (EDX) devices. The optical properties of the thin films were determined from the absorption spectrum using Shimadzu UV-3600 plus UVVis Spectrophotometer within the wavelength range of 300 $\mathrm{nm}-1000 \mathrm{~nm}$ for $\mathrm{ZnS}, \mathrm{CdS}$ and CdS/ZnS, 500- $2000 \mathrm{~nm}$ for $\mathrm{CoS}$ and $300-2000 \mathrm{~nm}$ for $\mathrm{CdS} / \mathrm{CoS}$ films.

\section{Results and Discussion}

\subsection{Structural Studies}

The XRD patterns of different substrates and the CdS thin films deposited on these substrates are shown in Figure 1. As it can be observed from this figure, the $\mathrm{CdS}$ thin film deposited on soda lime glass substrate has a single peak at $2 \theta$ $=26.69^{\circ}$ which is indexed to (111) plane of cubic structure (JCPDS \# 00-010-0454). The XRD pattern of $\mathrm{ZnS}$ thin film deposited on glass substrate has two very weak peaks at $2 \theta$ $=28.63^{\circ}$ and $47.97^{\circ}$ which were indexed to (111) and (220) planes of cubic phase (JCPDS \# 00-005-0566). The CdS/ZnS multilayer has similar diffraction pattern to that of $\mathrm{ZnS}$ thin films deposited on the glass substrate. This implies that new $\mathrm{CdS}$ phase has not been grown on the $\mathrm{ZnS}$ structure. Three peaks were observed at $2 \theta=20.29,22.32$ and $29.95^{\circ}$ on XRD pattern of $\mathrm{CoS}$ thin film deposited on soda lime glass substrate. Comparison of this pattern with the PDF files indicates that the CoS film consists of the mixtures of phases.

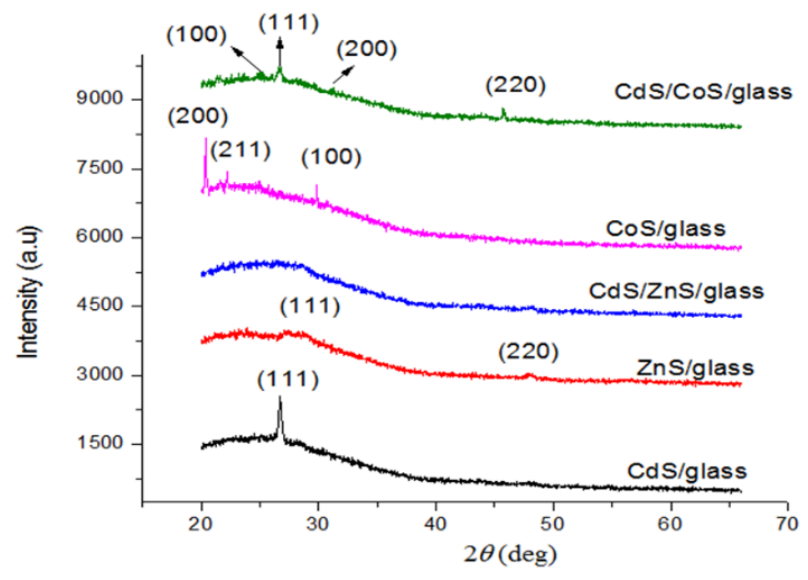

Fig.1: XRD patterns of $\mathrm{CdS}, \mathrm{CoS}$ and $\mathrm{ZnS}$ thin films deposited on glass and $\mathrm{CdS}$ thin films deposited on $\mathrm{CoS}$ and $\mathrm{ZnS}$ coated glass substrates. 
The peaks at $2 \theta=20.29^{\circ}$ and $29.95^{\circ}$ are diffractions from the hexagonal CoS (Pdf\# 01-1279) and cubic Co9S8 (Pdf\# 752023) respectively and the one at $2 \theta=22.32^{\circ}$ is due to either the hexagonal CoS (Pdf\# 01-1279) or the cubic Co9S8 (Pdf\# 190364) [39]. The CdS thin film deposited on CoS substrate has grown in both hexagonal and orthorhombic CdS structures which is manifested by four very weak peaks. The peaks at $2 \theta=24.9^{\circ}$ and 26.67 respectively represent (100) and (002) planes of the hexagonal CdS structure (JCPDS \# 01-07-2553) and the peaks at $2 \theta=31.2$ and $45.6^{\circ}$ consecutively represent (110) and (021) planes of orthorhombic CdS structure (JCPDS \# 00-043-0985). The structural analysis confirms that the substrate has significant impact on the crystal structure of CdS thin films. Comparable results showing the effect of substrates on the properties of the CdS thin films were reported by [21-24,40].

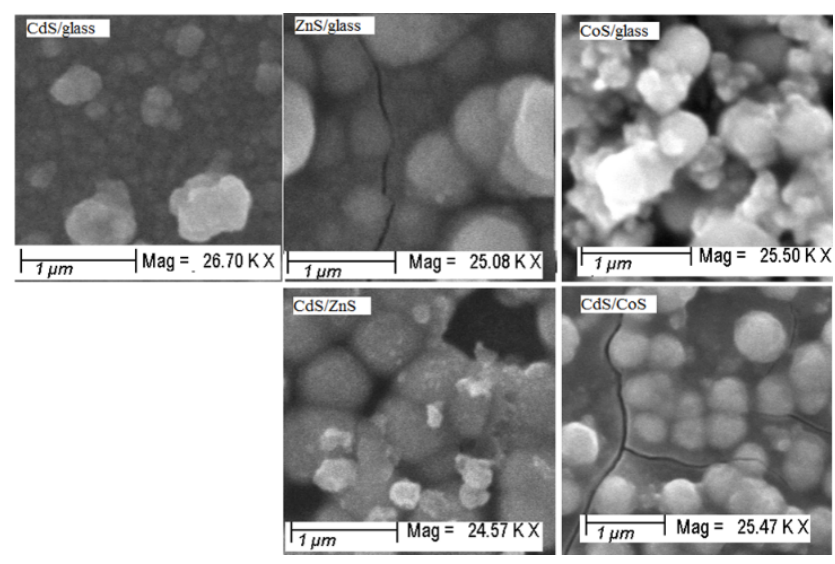

Fig.2: SEM micrographs of CdS thin films and the substrates used to deposit the films.

\subsection{Surface Morphology and Composition Analysis}

The surface morphology of the CdS/glass, ZnS/glass, $\mathrm{CoS} /$ glass, $\mathrm{CdS} / \mathrm{ZnS}$ and $\mathrm{CdS} / \mathrm{CoS}$ thin films are represented in Figure 2. The CdS thin film deposited on glass substrate has a uniformly covered surface morphology formed by spherical shaped grains of average size $125 \mathrm{~nm}$. The grains completely covered the substrate without pinholes and cracks. Except few larger grains on the most top surface, the film has uniform grain size distribution. The surface morphology of $\mathrm{ZnS}$ thin films revealed larger spherical grains of average size of $710 \mathrm{~nm}$. Some of the grains coalesce forming large grains and others have distinct grain boundaries. No pinholes were observed except few cracks. The surface morphology of $\mathrm{CdS} / \mathrm{ZnS}$ multilayer is similar to that of $\mathrm{ZnS}$ thin films grown on the glass substrate, however, the average grain size increased to $800 \mathrm{~nm}$ and few voids appeared. This result strengthens the XRD result showing that no distinct $\mathrm{CdS}$ phase is formed on $\mathrm{ZnS}$ layer, rather than diffusion of $\mathrm{Cd}$ and $\mathrm{S}$ in to the $\mathrm{ZnS}$ structure. The SEM micrograph of the CoS thin films deposited on the glass substrate shows non-compact spherical and irregular shaped grains with a number of voids. The SEM micrographs of $\mathrm{CdS} / \mathrm{CoS}$ signifies spherical surface grains of average size $450 \mathrm{~nm}$ on flat and compact background grains. No voids were observed on $\mathrm{CdS} / \mathrm{CoS}$ layer; however, cracks were appeared. Similar variation on the surface morphology of $\mathrm{CdS}$ thin films deposited on different substrates was reported by O'Brien and co-works [28].

The EDX spectra of the CdS thin films deposited on different substrates are shown in Figure 3. As confirmed by EDX investigation, the ratio of Cd:S, $\mathrm{Zn}: \mathrm{S}$ and $\mathrm{Co}: \mathrm{S}$ in the $\mathrm{CdS} /$ glass, $\mathrm{ZnS} /$ glass and $\mathrm{CoS} /$ glass thin films are 49: 51, 50:50 and 39:61 respectively. In CdS/ZnS, the element ratio of $\mathrm{Cd}: \mathrm{Zn}: \mathrm{S}$ is 19:26:55, which shows a slight dominance of $\mathrm{S}$ in the film. The dominance of $\mathrm{Zn}$ over $\mathrm{Cd}$ could be resulted from very thin layer of $\mathrm{CdS}$ over the $\mathrm{ZnS}$. However, for $\mathrm{CdS} / \mathrm{CoS}$ films $\mathrm{S}$ has significant dominance over the metal ions with $\mathrm{Cd}: \mathrm{Co}: \mathrm{S}$ percentage composition of 17: 16: 67 which is resulted from the CoS layer as we reported in our previous work [39].

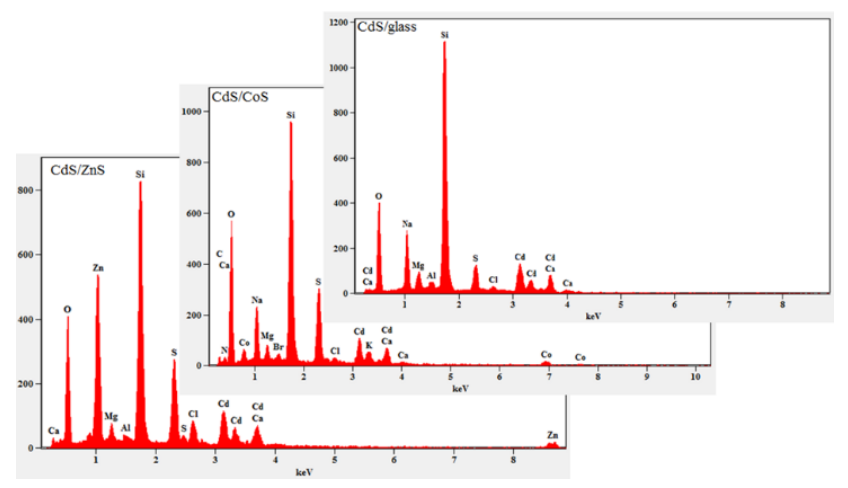

Fig. 3: EDX spectrum of $\mathrm{CdS} / \mathrm{galss}, \mathrm{CdS} / \mathrm{CoS}$ and $\mathrm{CdS} / \mathrm{ZnS}$ thin films.

\subsection{Optical Properties}

The plot of product of absorbance and photon energy squared $(A h v)^{2}$ versus photon energy $(h v)$ of the single and multilayer films are shown in Figure 4 (a) and (b). The plot for $\mathrm{ZnS} / \mathrm{glass}$ thin film revealed two transition edges (Figure4 (a)). The transition at low energy photon could be due to defect states in the crystal structure of the film, however, the transition at photon energy of $2.6 \mathrm{eV}$ is due a fundamental transition. For $\mathrm{CdS} / \mathrm{ZnS}$ multilayer thin film, the two transition edges in the $\mathrm{ZnS}$ thin film changed to a single broad transition edge. The result implies that the defect states in $\mathrm{ZnS}$ thin films were significantly minimized by depositing $\mathrm{CdS}$ on $\mathrm{ZnS}$ layer. The $\mathrm{ZnS} /$ glass and $\mathrm{CdS} / \mathrm{ZnS}$ layers have higher absorbance of visible and near infrared light than the CdS/glass layer. This could be resulted from the higher thickness and defect states of the former layers. Similarly, the CoS/glass and $\mathrm{CdS} / \mathrm{CoS}$ layers have higher absorbance than $\mathrm{CdS} /$ glass layer in the same region 
of light. However, the reverse is true in the infrared region.

The energy band gaps of the thin films were obtained using Stern relationship (Eqn. 1) at the near-fundamental absorption edge [41].

$$
A=\frac{\left[k\left(h v-E_{g}\right)\right]^{\frac{n}{2}}}{h v}
$$

where $A$ is absorbance, $k$ is a constant, $h$ is the Planck's constant, $v$ is the frequency of the radiation, and $n$ is 1 for the direct transition which is true for almost all compound semiconductors and 4 for the indirect transition. In the case of direct transition $(A h v)^{2}$ and the photon energy $(h v)$ (Eqn.1) has linear relation in the region next to the onset of fundamental absorption [42].
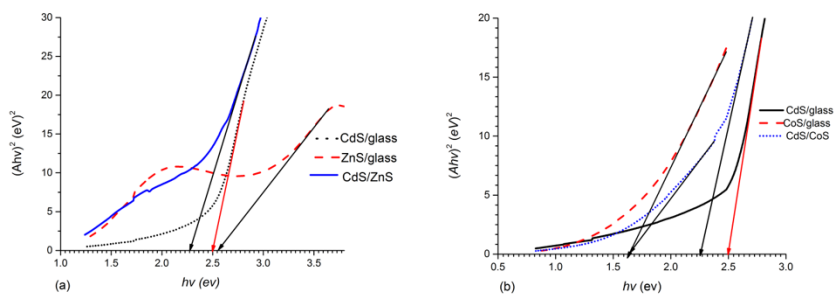

Fig. 4: Optical band gap of different substrates and the CdS thin films deposited on these substrates.

The band gap energy $\left(\mathrm{E}_{\mathrm{g}}\right)$ was obtained by extrapolating the linear portion of the $(A h v)^{2}$ vs $(h v)$ curve towards $h v$ axis . The band gaps of the $\mathrm{CdS} /$ glass, $\mathrm{ZnS} /$ glass, $\mathrm{CdS} / \mathrm{ZnS}$ and CoS/glass thin films are equal to $2.5,2.6,2.3$ and $1.6 \mathrm{eV}$ respectively (Figure 4). The $\mathrm{CdS} / \mathrm{CoS}$ multilayer has two band gaps of 1.6 and $2.27 \mathrm{eV}$ corresponding to $\mathrm{CoS}$ and $\mathrm{CdS}$ phases, respectively. The presence of a single bandgap in $\mathrm{CdS} / \mathrm{ZnS}$ confirms the homogenization of $\mathrm{ZnS}$ and $\mathrm{CdS}$ layers instead of forming their own phases. The decrease in band gap when $\mathrm{CdS}$ deposited on $\mathrm{ZnS}$ and $\mathrm{CoS}$ could be due to strain and increase in the grain size as shown in SEM micrograph of $\mathrm{CdS} / \mathrm{ZnS}$ and $\mathrm{CdS} / \mathrm{CoS}$ films (Figure 2) [43, 44]. In the case of $\mathrm{CdS} / \mathrm{CoS}$, the band gap decrease can also be resulted from the substitution of some of the $\mathrm{Cd}$ ions specially at the interface region by relatively larger atomic radius Co ions [45].

\section{Conclusions}

The CdS thin films were synthesized on different substrates by solution growth technique from a solution of cadmium acetate, thioacetamide and $N a_{2}$ EDTA in acidic condition. The XRD investigation confirmed that the type of substrate has significant influence on the growth and crystal structure of the CdS thin films. The CdS thin film deposited on soda lime glass substrate was grown in cubic structure and the one grown on $\mathrm{ZnS}$ substrate forms a homogenized phase with cubic $\mathrm{ZnS}$ structure. The XRD pattern of $\mathrm{CdS} / \mathrm{CoS}$ multilayer shows a mixture of hexagonal and orthorhombic CdS structures. The single and multilayered CdS thin films deposited on different substrates possessed different morphology in terms of shape and size of grains, voids and cracks. A stochiometric $\mathrm{CdS}$ thin film was deposited on a glass substrate, however, films deposited on $\mathrm{ZnS}$ and $\mathrm{CoS}$ substrate are dominated by sulfur. The optical bandgaps of the $\mathrm{CdS}$ films on $\mathrm{ZnS}$ and $\mathrm{CoS}$ substrates decreased as compared to that of deposited on a glass substrate. The structural, morphological and optical results confirmed that $\mathrm{CdS}$ thin film deposited on $\mathrm{ZnS}$ substrate forms homogenized phase with cubic $\mathrm{ZnS}$ structure and that deposited on $\mathrm{CoS}$ substrate forms a mixture of hexagonal and orthorhombic CdS phases. The present investigations showed that substrate has significant influence on structural, morphological, compositional and optical properties of the CdS thin films.

\section{Acknowledgement}

The authors thankfully acknowledge Hawassa University for funding this research work.

\section{References}

[1] Pandya, S.G., Preparation and characterization of cadmium sulphide nanocrystalline thin film grown by chemical method. International Journal of Recent Scientific Research., 7, 14887-14890(2016).

[2] Anbarasi, M., V. Nagarethinam, and A. Balu, Studies on the physical properties of undoped AND Zn-doped CdS thin films prepared by spray pyrolysis technique using perfume atomizer. Indian J. Sci., 13(38), 48-52(2015)

[3] Lim, D., J. Lee, and W. Song, Improvement of the characteristics of chemical bath deposition-cadmium sulfide films deposited on an $\mathrm{O} 2$ plasma-treated polyethylene terephthalate substrate. Thin Solid Films.,546, 317320(2013).

[4] Han, J.-f., G.-h. Fu, V. Krishnakumar, H.-J. Schimper, C. Liao, W. Jaegermann, and M. Besland, Studies of CdS/CdTe interface: Comparison of CdS films deposited by close space sublimation and chemical bath deposition techniques. Thin Solid Films., 582, 290-294 (2015).

[5] Feldmeier, E., A. Fuchs, J. Schaffner, H.-J. Schimper, A. Klein, and W. Jaegermann, Comparison between the structural, morphological and optical properties of CdS layers prepared by Close Space Sublimation and RF magnetron sputtering for CdTe solar cells. Thin Solid Films,. 519(21), 75967599(2011).

[6] Tomakin, M., M. Altunbaş, E. Bacaksiz, and Ş. Çelik, Current transport mechanism in CdS thin films prepared by vacuum evaporation method at substrate temperatures below room temperature. Thin Solid Films., 520(7), 2532-2536(2012).

[7] Hodes, G., Chemical solution deposition of semiconductor films. 2002: CRC press.

[8] Barote, M., A. Yadav, and E. Masumdar, Synthesis, 
characterization and photoelectrochemical properties of nCdS thin films. Physica B: Condensed Matter., 406(10), 1865-1871(2011).

[9] Oladeji, I.O. and L. Chow, Synthesis and processing of $\mathrm{CdS} / \mathrm{ZnS}$ multilayer films for solar cell application. Thin Solid Films., 474(1-2), 77-83(2005).

[10] Al-Hussam, A.M. and S.A.-J. Jassim, Synthesis, structure, and optical properties of CdS thin films nanoparticles prepared by chemical bath technique. Journal of the Association of Arab Universities for Basic and Applied Sciences., 11(1), 2731(2012).

[11] Chu, J., Z. Jin, W. Wang, H. Liu, D. Wang, J. Yang, and Z. Hong, Influence of anionic concentration and deposition temperature on formation of wurtzite CdS thin films by in situ chemical reaction method. Journal of Alloys and Compounds., 517, 54-60(2012).

[12] Khallaf, H., G. Chai, O. Lupan, L. Chow, S. Park, and A. Schulte, Investigation of aluminium and indium in situ doping of chemical bath deposited CdS thin films. Journal of Physics D: Applied Physics., 41(18), 185304(2018).

[13] Sharkey, J.J., V. Dhanasekaran, C.W. Lee, and A.J. Peter, Microstructural parameters and optical constants of CdS thin films synthesized with various bath temperature. Chemical Physics Letters., 503(1-3), 86-90(2011).

[14] Liu, F., Y. Lai, J. Liu, B. Wang, S. Kuang, Z. Zhang, J. Li, and Y. Liu, Characterization of chemical bath deposited CdS thin films at different deposition temperature. Journal of Alloys and Compounds., 493(1-2), 305-308(2010)

[15] Ochoa-Landín, R., M. Sandoval-Paz, M. Ortuño-López, M. Sotelo-Lerma, and R. Ramírez-Bon, Observations on the influence of $\mathrm{pH}$ control on the properties of chemically deposited CdS films in an ammonia-free system. Journal of Physics and Chemistry of Solids., 70(6), 1034-1041(2009).

[16] Prabahar, S. and M. Dhanam, CdS thin films from two different chemical baths-structural and optical analysis. Journal of Crystal growth., 285(1-2), 41-48 ( 2005).

[17] Kariper, A., E. Güneri, F. Göde, C. Gümüş, and T. Özpozan, The structural, electrical and optical properties of CdS thin films as a function of $\mathrm{pH}$. Materials Chemistry and Physics., 129(1-2), 183-188(2011).

[18] Guillén, C., M. Martınez, and J. Herrero, Accurate control of thin film CdS growth process by adjusting the chemical bath deposition parameters. Thin Solid Films., 335(1-2), 3742(1998).

[19] Alexander, J.N., S. Higashiya, D. Caskey Jr, H. Efstathiadis, and P. Haldar, Deposition and characterization of cadmium sulfide (CdS) by chemical bath deposition using an alternative chemistry cadmium precursor. Solar Energy Materials and Solar Cells., 125, 47-53(2014).

[20] Çetinörgü, E., C. Gümüş, and R. Esen, Effects of deposition time and temperature on the optical properties of air-annealed chemical bath deposited CdS films. Thin Solid Films,. 515(4), 1688-1693(2006).

[21] Cao, M., Y. Sun, J. Wu, X. Chen, and N. Dai, Effects of cadmium salts on the structure, morphology and optical properties of acidic chemical bath deposited CdS thin films. Journal of Alloys and Compounds., 508(2), 297-300(2010).

[22] Lee, J.-H., Influence of substrates on the structural and optical properties of chemically deposited CdS films. Thin Solid Films., 515(15), 6089-6093(2007)

[23] Oliva, A., R. Castro-Rodrıguez, O. Ceh, P. Bartolo-Perez, F. Caballero-Briones, and V. Sosa, First stages of growth of CdS films on different substrates. Applied Surface Science.,148(12), 42-49(1999).

[24] Martínez, M., C. Guillen, and J. Herrero, Cadmium sulphide growth investigations on different $\mathrm{SnO} 2$ substrates. Applied Surface Science., 140(1-2), 182-189(1999).

[25] Castro-Rodríguez, R., A. Oliva, V. Sosa, F. Caballero-Briones, and J. Pena, Effect of indium tin oxide substrate roughness on the morphology, structural and optical properties of CdS thin films. Applied Surface Science., 161(3-4), 340-346(2000).

[26] Long, F., W.-M. Wang, Z.-k. Cui, L.-Z. Fan, Z.-g. Zou, and T.-k. Jia, An improved method for chemical bath deposition of $\mathrm{ZnS}$ thin films. Chemical Physics Letters., 462(1-3), 8487(2008).

[27] Luque, P., M. Quevedo-Lopez, and A. Olivas, Influence of deposition time on $\mathrm{ZnS}$ thin film growth over $\mathrm{SiO} 2$ and glass substrates. Materials Letters., 106, 49-51(2013).

[28] O’Brien, P., E. Hill, M. Malik, and M. Toohey, Chemical bath deposition of cadmium sulphide on silicon nitride: Influence of surface treatment on film growth. Materials Letters., 61(1), 284-287(2007).

[29] Chu, S., C. Cohen-Tannoudji, and W. Phillips, Nobel Lectures in Physics: 1996-2000. 2003, World Scientific Pub. Co. Inc.

[30] Razeghi, M., Fundamentals of solid state engineering. 2006: Springer.

[31] Frensley, W.R., Heterostructure and quantum well physics, in VLSI Electronics Microstructure Science. 1994, Elsevier. p. $1-24$.

[32] García-Barrientos, A., H. Gomez-Pozos, E. Villicaña-Ortiz, and L. Cruz-Netro, Comparative Study of CdS and CdS/ZnS Thin Films Deposited by CBD as a Buffer Layer Solar Cell. Microscopy and Microanalysis., 24(S1), 1548-1549(2018).

[33] Echendu, O.K. and I.M. Dharmadasa, Graded-bandgap solar cells using all-electrodeposited $\mathrm{ZnS}, \mathrm{CdS}$ and CdTe thinfilms. Energies., 8(5), 4416-4435(2015).

[34] Szczerbakow, A., M. Godlewski, E. Dynowska, V.Y. Ivanov, K. Swiatek, E. Goldys, and M. Phillips, Structure, surface morphology and optical properties of thin films of $\mathrm{ZnS}$ and CdS grown by atomic layer epitaxy. Acta Physica PolonicaSeries A General Physics., 94(3), 579-582(1998).

[35] Valkonen, M.P., T. Kanniainen, S. Lindroos, M. Leskelä, and E. Rauhala, Growth of $\mathrm{ZnS}, \mathrm{CdS}$ and multilayer $\mathrm{ZnS} / \mathrm{CdS}$ thin films by SILAR technique. Applied surface science., 115(4), 386-392(1997).

[36] Kumar, D.P., H. Park, E.H. Kim, S. Hong, M. Gopannagari, D.A. Reddy, and T.K. Kim, Noble metal-free metal-organic framework-derived onion slice-type hollow cobalt sulfide nanostructures: Enhanced activity of $\mathrm{CdS}$ for improving 
photocatalytic hydrogen production. Applied Catalysis B: Environmental., 224,. 230-238(2018).

[37] Qiu, B., Q. Zhu, M. Du, L. Fan, M. Xing, and J. Zhang, Efficient solar light harvesting CdS/Co9S8 hollow cubes for Z-scheme photocatalytic water splitting. Angewandte Chemie International Edition., 56(10), 2684-2688(2017).

[38] Reddy, D.A., H. Park, M. Gopannagari, E.H. Kim, S. Lee, D.P. Kumar, and T.K. Kim, Designing CdS Mesoporous Networks on Co-C@ Co9S8 Double-Shelled Nanocages as RedoxMediator-Free Z-Scheme Photocatalyst. ChemSusChem.,11(1), 245-253(2018).

[39] Abza, T., D.G. Dadi, F.G. Hone, T.C. Meharu, G. Tekle, E.B. Abebe, and K.S. Ahmed, Characterization of Cobalt Sulfide Thin Films Synthesized from Acidic Chemical Baths. Advances in Materials Science and Engineering., 2020.

[40] Cao, M., L. Li, B. Zhang, J. Huang, K. Tang, H. Cao, Y. Sun, and Y. Shen, Influence of substrates on the structural and optical properties of ammonia-free chemically deposited CdS films. Journal of alloys and compounds., 530, 81-84(2012).

[41] Abza, T., F.K. Ampong, F.G. Hone, R.K. Nkum, and F. Boakye, Preparation of cadmium zinc sulfide (Cd1- xZnxS) thin films from acidic chemical baths. Thin Solid Films,. 666, 28-33(2018).

[42] Nasr, T.B., N. Kamoun, M. Kanzari, and R. Bennaceur, Effect of $\mathrm{pH}$ on the properties of $\mathrm{ZnS}$ thin films grown by chemical bath deposition. Thin solid films., 500(1-2), 4-8(2006).

[43] Das, N., P. Ghosh, M. Mitra, and K. Chattopadhyay, Effect of film thickness on the energy band gap of nanocrystalline $\mathrm{CdS}$ thin films analyzed by spectroscopic ellipsometry. Physica E: Low-Dimensional Systems and Nanostructures., 42(8), 2097 2102(2010)

[44] Makhdoumi-Kakhaki, Z., A. Youzbashi, P. Sangpour, N. Naderi, and A. Kazemzadeh, Effects of film thickness and stoichiometric on the electrical, optical and photodetector properties of CdS quantum dots thin films deposited by chemically bath deposition method at different bath temperature. Journal of Materials Science: Materials in Electronics., 27(12), 12931-12939(2016).

[45] Saravanakumar, S., R. Chandramohan, R. Premarani, J.J. Devadasan, and J. Thirumalai, Studies on Dilute Magnetic Semiconducting Co-Doped CdS Thin Films Prepared by Chemical Bath Deposition method. Journal of Materials Science: Materials in Electronics., 28(16), 12092-12099 (2017). 